\title{
Numerical modelling of solar thermal effects on street canyon flow under calm or weak wind conditions
}

\author{
Stefanidou M.K., Bekri E.S., Yannopoulos P.C.* \\ Environmental Engineering Laboratory, Department of Civil Engineering, University of Patras, 26504 Patras, Greece \\ Received: 28/01/2019, Accepted: 01/08/2019, Available online: 09/12/2019 \\ *to whom all correspondence should be addressed: e-mail: yannopp@upatras.gr \\ https://doi.org/10.30955/gnj.003035
}

\begin{abstract}
The present study simulates the flow and temperature fields in a street canyon caused by solar heating of road and building surfaces, in either calm and weak wind conditions. Six scenarios, formed by changing the sources of heat fluxes, the wind speed $\left(0,1\right.$ and $\left.3 \mathrm{~m} \mathrm{~s}^{-1}\right)$ and direction $( \pm)$, are examined, at 12:00 solar time during June 21 in the city of Patras. A $1000-\mathrm{W} \mathrm{m}^{-2}$ heat flux is considered to come out from the road surface and/or 400-W $\mathrm{m}^{-2}$ heat flux from the left building face. These values correspond to the most intense solar radiation conditions. A computational fluid dynamics (CFD) simulation is performed and the results show that the weak winds cause increased temperatures near the building faces compared to calm conditions, due to intense vortices that entrap air masses, while moderate winds contribute to an improvement of temperatures below those for calm conditions. The entrapment of air masses may also cause increase of pollutant concentrations deteriorating both outdoor and indoor air quality and thermal comfort conditions.
\end{abstract}

Keywords: Street canyon, solar heating, thermal comfort, wind speed, CFD.

\section{Introduction}

In most modern cities, the building structure is developed in various patterns of urban grids resulting to the formulation of the so-called "street canyons". The urban street canyon is a principal structure that characterizes the form of a whole city. It is formed by continuous buildings on both sides of a narrow street (Zakaria et al., 2014).

During the last decades there is an increased concern over the citizen's health in urban areas due the air quality (Schwela, 2000) and particularly in areas dominated by street canyons. Many researchers have focused to the urban microclimate and its effect on the residents' health quality and thermal comfort conditions (Nazarian et al., 2017). Many factors affect urban air quality and the pollutant dispersion in street canyons such as ambient conditions (i.e. wind speed and direction, temperature, humidity), urban planning, street canyon dimensions, the shape and the size of the buildings (De Lieto Vollaro et al., 2014), solar radiation (Bottillo et al., 2014; Wang et al., 2014), orientation and traffic emissions (Venkatram and Schutle, 2018).

There are many studies that consider the thermal effect as a very important factor, which influences the air flow and pollutant dispersion in a street canyon (see, for example, Kim and Baik, 2001; Xie et al., 2005; Wang et al., 2011). Also, the materials and geometry play a significant role regarding the heat exchange between the urban surface and atmosphere (Offerle et al., 2007). Within a street canyon, the main source of heat transferred into the building faces and to ground surface is the direct solar radiation, the diffused radiation and the reflected radiation from the ground surface. Due to buoyancy, the air above the ground and within the street canyon is moving upward (Kim and Baik, 2001; Louka et al., 2002). In some studies, wind-tunnel experiments and field observations that investigate the mean flow in street canyons have been performed (Uehara et al., 2000). Their results indicate that thermal changes alter the flow field in street canyons.

Now-a-days simulations with Computational Fluid Dynamics (CFD) are used to analyze the urban microclimate (Toparlar et al., 2017) and more particularly to investigate numerically the flow field in terms of thermal effects (Herbert and Herbert, 2002; Xie et al., 2006; Dimitrova et al., 2009; Santiago et al., 2014). Some studies use the large eddy simulation (LES) method to assess the thermal effects on air flow and pollutant dispersion inside urban street canyons. (Park et al., 2012; Yaghoobian et al., 2014). An idealized two-dimensional model has been proposed in order to analyze the temperature effects inside and above urban canyons (Xie et al., 2007; Li et al., 2012; Battista and Mauri, 2016). To the best of our knowledge, there is a very restricted number of studies of the thermal effects on the flow and temperature field of street canyons in calm or weak wind conditions (Kim and Baik, 2001; Li et al., 2012).

The present work studies numerically the flow field caused by the solar heating of road and building faces of a street canyon. A two-dimensional model that simulates 
the above air street canyon effects in calm or weak wind conditions is used. Although such a model has the shortcomings of assuming connection of the road crossing with the canyon, it has the advantages of shorter computational time and memory usage than a three dimensional (3D) model. However, the present study will constitute a valuable stage to proceed to a $3 \mathrm{D}$ model in the next future work. The present simulation considers the non-symmetrical conditions of solar energy emitted by the road and the building faces, aiming to investigate the air temperature distribution near the building faces and the adverse effects on spreading of air pollutants for extreme radiation conditions. This situation may affect outdoor and indoor comfort conditions.

\section{Problem definition and modelling}

\subsection{Model approximations}

The street canyon is simulated as a long channel of a 2D cross-section. Since the street canyon is interrupted by cross roads, which constitute side openings operating as free boundaries, the street canyon is considered having longitudinal side slots near the street, as shown in Figures $1(a)$ and $1(b)$. These openings allow air circulation from both sides, approximating as much as possible the real flow conditions in the street canyon, a fact impossible to consider otherwise in a 2D approximation. If the street canyon were assumed without the above slots, the upward flow initiating by the heat of the road surface would cause a pressure drop at the lower area of the canyon, which in turn would cause more intense vortices. It is estimated that the latter will differ from the real situation. The street is located at the middle of the domain bottom. The computational domain includes a much wider area than the street canyon area, though not actually free from obstacles in a city, since it is surrounded by other buildings which hamper the free air flow. The number of grid nodes used is 100160 consisted by 33137 elements of size $0.01 \mathrm{~m}$ in the area of interest and $0.02 \mathrm{~m}$ in the rest of the domain. Across the road width, 39 grid lines were placed. We have done computations with half the number of nodes and about double element sizes and we have noticed small differences.
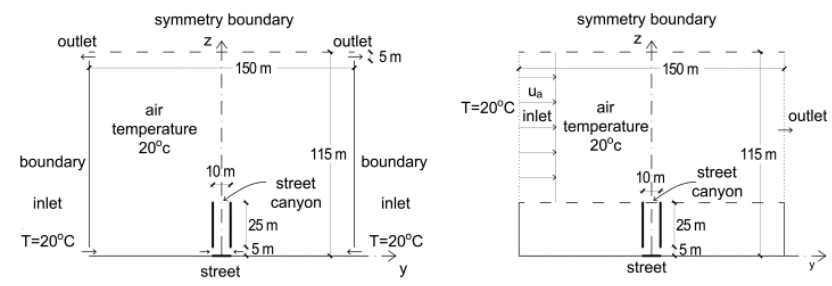

(a)

(b)

Figure 1. Configuration of the 2D flow field due to heat fluxes coming from road and building walls within and above a street canyon, simulated in an ample computational domain: (a) Calm conditions; (b) wind conditions over the street canyon. The road direction is from west to east

Our study analyses the flow and temperature field in a street canyon under six scenarios, concerning sources of the heat flux for extreme solar energy conditions, i.e. the orientation of the street canyon is considered perpendicular to the vertical plane defining the maximum solar height at 12:00 solar time of June 21 . The heat coming on a surface is direct, diffuse and ground-reflected radiation. Thus, the heat flux of a surface considered herein includes the three kinds of heating. To assign realistic values of radiative fluxes, the most adverse situation recorded by the pyranometer operating on the roof of the building of the Civil Engineering Department of the University of Patras has been selected.

The values recorded at solar time interval 12:00-13:00 of June 21 for the period 2014-2018 varied in the range (913-1139 W/m²). The following scenarios are examined:

Scenario I with road heat flux only; Scenario II with left wall heat flux only; Scenario III with road and left wall heat fluxes; Scenario IV with road and left wall heat fluxes, as Scenario III, and additionally left-to-right wind of low speed $\left(u_{a}=1 \mathrm{~m} \mathrm{~s}^{-1}\right)$ over the buildings, Scenario $\mathrm{V}$ with road and left wall heat fluxes, as Scenario III, and additionally with right-to-left wind of low speed $\left(u_{a}=-1 \mathrm{~m} \mathrm{~s}^{-1}\right)$, and Scenario VI with road and left wall heat fluxes, as Scenario III, and additionally right-to-left wind of moderate speed $\left(u_{a}=-3 \mathrm{~m} \mathrm{~s}^{-1}\right)$.

\subsection{Model set-up and boundary conditions}

The governing equations of the problem are the unsteady Reynolds-Averaged Navier-Stokes (RANS) equations, which have been solved employing the pressure-based version along with the standard $k-\varepsilon$ turbulence model and the Boussinesq approximation for buoyancy effects:

\section{Continuity equation}

$$
\frac{\partial v}{\partial y}+\frac{\partial w}{\partial z}=0
$$

$y$-momentum equation

$$
\frac{\partial v}{\partial t}+\frac{\partial\left(v^{2}+v^{\prime 2}\right)}{\partial y}+\frac{\partial\left(w v+w^{\prime} v^{\prime}\right)}{\partial z}=-\frac{\partial p}{\rho_{0} \partial y}+v\left(\frac{\partial^{2} v}{\partial y^{2}}+\frac{\partial^{2} v}{\partial z^{2}}\right)
$$

$z$-momentum equation

$$
\frac{\partial w}{\partial t}+\frac{\partial\left(w v+w^{\prime} v^{\prime}\right)}{\partial y}+\frac{\partial\left(w^{2}+w^{\prime 2}\right)}{\partial z}=g \beta\left(T-T_{0}\right)-\frac{\partial p}{\rho_{0} \partial z}+v\left(\frac{\partial^{2} w}{\partial y^{2}}+\frac{\partial^{2} w}{\partial z^{2}}\right)
$$

Energy equation

$$
\frac{\partial T}{\partial t}+\frac{\partial\left(v T+v^{\prime} T^{\prime}\right)}{\partial y}+\frac{\partial\left(w T+w^{\prime} T^{\prime}\right)}{\partial z}=\alpha\left(\frac{\partial^{2} T}{\partial y^{2}}+\frac{\partial^{2} T}{\partial z^{2}}\right)+\frac{J}{\rho_{0} C_{p}}
$$

where $w$ is the mean vertical velocity, $v$ is the mean horizontal velocity, $w^{\prime}$ and $v^{\prime}$ are their corresponding fluctuations due to turbulence, $g$ is the gravity acceleration, $p$ is the pressure, $\rho=\rho_{0}-\beta \rho_{0}\left(T-T_{0}\right)$ is the local density of air of temperature $T, \rho_{0}$ and $T_{0}$ are the ambient density and temperature, $\beta$ is the thermal expansion coefficient, $v$ is the air kinematic viscosity, $\alpha$ is the thermal diffusivity of air, $C_{p}$ is the isobaric heat capacity, $J$ is the source term representing the rate per unit volume heat production, which includes the heat coming from a source of heat, both directly (solar radiation) and indirectly (diffused radiation and reflected radiation from the ground surface); $w^{\prime 2}, w^{\prime} T, v^{\prime} T^{\prime}$ are the local mean vertical velocity and tracer fluxes due to 
turbulence fluctuations of $w, v$ and $T$. It is noted that for calculating concentrations $c$ of a conservative air pollutant, a similar equation to equation (4) is used. The turbulent fluxes are calculated throughout the use of the well-known $k-\varepsilon$ turbulence model provided with default values for wall roughness and other parameters.

The ANSYS ${ }^{\circledR}$ Fluent 19.1 computational fluid dynamics (CFD) software has been used to obtain the flow and temperature fields in the street canyon. The geometry of the model was prepared using the software ANSYS ${ }^{\circ}$ Design Modeler. A 10-m wide road and 25-m high building walls are assigned, placed $5 \mathrm{~m}$ above the road level in order to simulate the cross-road effect, as justified in section 2.1. The computational domain was $150-\mathrm{m}$ wide and $115-\mathrm{m}$ high for either calm or wind conditions. In the first case (Figure 1a), the domain has two openings of $5 \mathrm{~m}$ at the side walls near the bottom to allow entrance ambient air of $20^{\circ} \mathrm{C}$ and other two outlets near the top of side walls to allow the air exit. In the second case (Figure 1b), a wind of horizontal direction perpendicular to the street canyon over the buildings with speed of either $u_{a}= \pm 1 \mathrm{~m} \mathrm{~s}^{-1}$ or $u_{a}=-3 \mathrm{~m} \mathrm{~s}^{-1}$ has been assigned. For both cases, the initial temperature of the ambient air was set to $20^{\circ} \mathrm{C}$. The model domain was discretized using rectangular cells. For greater accuracy, the mesh has been refined near the road and building walls. Double precision has been used to reduce the error of numerical calculation.

The non-slip boundary condition has been assigned at the road surface, on building walls, bottom and side boundaries of the computational domain, while the symmetry condition on the top boundary. The temperature of air entering the computational domain has been set to $20^{\circ} \mathrm{C}$. A $1000-\mathrm{W} \mathrm{m}^{-2}$ heat flux is considered to come into the computational domain from the road during the midday hours for Scenarios I, III, IV, V and VI. For Scenarios II, III, IV, V and VI a 400-W $\mathrm{m}^{-2}$ heat flux is considered to come into the computational domain from the left wall of the street canyon. A zero value of initial velocity has been assigned in the entire computational domain for all scenarios. In the computational domain over the street canyon and buildings, the following values of wind speed $u_{a}$ have been assigned: $1 \mathrm{~m} \mathrm{~s}^{-1}$ for Scenario IV; $-1 \mathrm{~m} \mathrm{~s}^{-1}$ for Scenario V; and $-3 \mathrm{~m} \mathrm{~s}^{-1}$ for Scenario VI. The duration of numerical calculations was approximately two minutes to attain quasi steady-state conditions. The unsteady mode of equations is necessary to get physical solutions, since clear steady-state conditions are impossible to attain in a finite space. On the other hand, the time contributes as under relaxation process improving solution convergence.

\section{Results and discussion}

\subsection{Vertical and horizontal velocity profiles}

The horizontal cross-section profiles of vertical velocities at several heights above road are shown in Figure 2 for the six scenarios simulated. As expected, the velocity profile for Scenario I is symmetrical due to symmetrical heat source, initial and boundary conditions, while the profiles for all other scenarios (II, III, IV, V and VI), which have non-symmetrical heat sources, are non-symmetrical. The values of velocity near the left building face range from -0.85 to $0.4 \mathrm{~m} \mathrm{~s}^{-1}$. The minimum value $-0.85 \mathrm{~m} \mathrm{~s}^{-1}$ is found in the region between the middle and the top of the left side wall of the street canyon (17.5 to $30 \mathrm{~m}$ above road) for Scenarios II and III. The values of velocity near the right building face range from -0.65 to $0.6 \mathrm{~m} \mathrm{~s}^{-1}$, both occurring for Scenario VI. The minimum value $-0.65 \mathrm{~m} \mathrm{~s}^{-1}$ is found at the lower region of the building face, while the maximum value $0.6 \mathrm{~m} \mathrm{~s}^{-1}$ is found in the region between the middle of the building height ( $17.5 \mathrm{~m}$ above the road). Scenarios IV and V show somewhat lower vertical velocities $\left(-0.28\right.$ to $\left.0.36 \mathrm{~m} \mathrm{~s}^{-1}\right)$ at the middle of the left building height, while the velocities range from 0 to $0.36 \mathrm{~m} \mathrm{~s}^{-1}$ near the right building face for Scenario IV, with $0.36 \mathrm{~m} \mathrm{~s}^{-1}$ occurring in the wall region around $10 \mathrm{~m}$ above road.
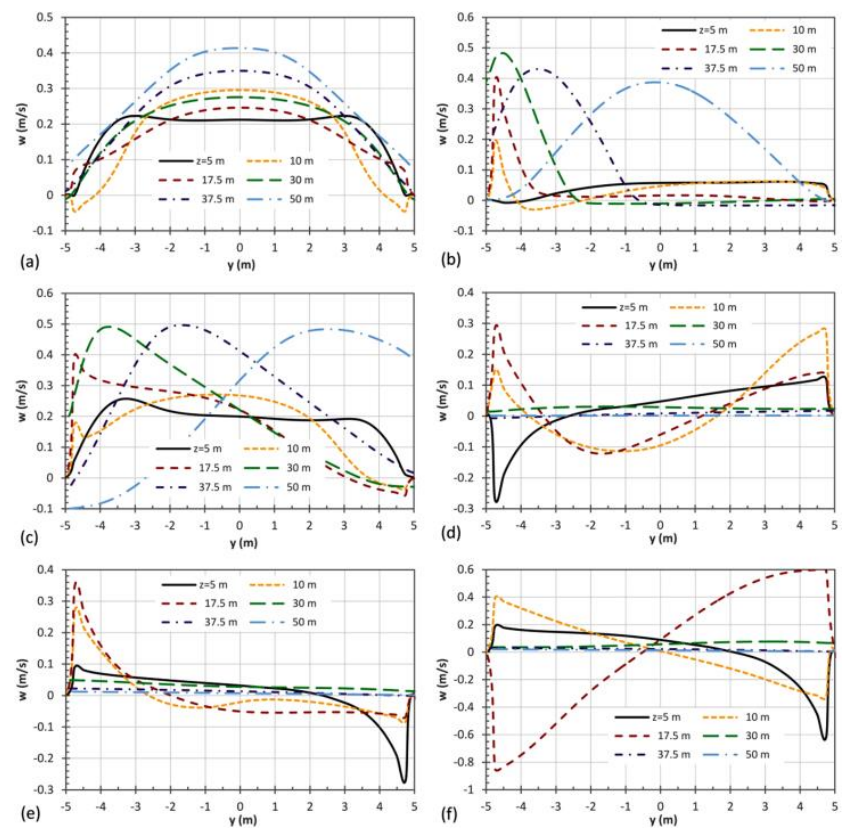

Figure 2. Horizontal cross-section profiles of vertical velocities at several heights for the scenarios simulated: (a) Scenario I; (b) Scenario II; (c) Scenario III; (d) Scenario IV; (e) Scenario V; and (f) Scenario VI

For Scenario I, where the air motions are initiated by buoyant forces due to road heat flux only, the maximum velocities at several height levels range from 0.2 to $0.42 \mathrm{~m}$ $\mathrm{s}^{-1}$ and they are observed at the symmetric vertical plane of the street canyon. For all other scenarios (II throughout VI), where road and/or left wall heat fluxes are assigned, the maximum velocities are observed near the walls. This is good for comfort and pollution quality conditions, because the air movements near building faces remove heat by convection away from buildings and may reduce air pollutant levels. Scenarios IV, V and VI with wind speed over the building height, show nearly zero vertical velocities at the top of the street canyon ( $30 \mathrm{~m}$ above the road), which means a sort of air and pollutant trapping. In contrast, Scenarios I, II and III indicate maximum velocity 
values in the range $\left(0.3\right.$ to $\left.0.5 \mathrm{~m} \mathrm{~s}^{-1}\right)$ at the top of the street canyon. The maximum vertical velocities at larger heights than $30 \mathrm{~m}$ are approximately the same 0.4 to $\left.0.5 \mathrm{~m} \mathrm{~s}^{-1}\right)$. It is noted that this is a characteristic phenomenon occurring in two-dimensional plumes (Yannopoulos, 2006).
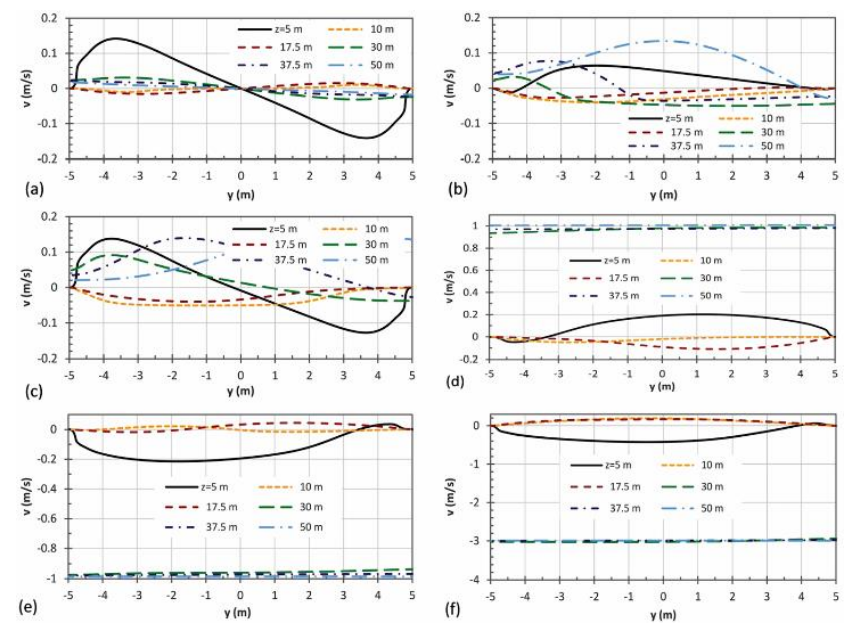

Figure 3. Horizontal cross-section profiles of transverse velocities at several heights for the scenarios simulated: (a) Scenario I; (b) Scenario II; (c) Scenario III; (d) Scenario IV; (e) Scenario V and (f) Scenario VI

The horizontal cross-section profiles of horizontal velocities at several heights above the road of the street canyon are shown in Figure 3 for the six scenarios simulated. The absolute maximum values of horizontal velocities $\left(|v| \leq 0.2 \mathrm{~m} \mathrm{~s}^{-1}\right)$ are observed at the lowest level of the buildings, as expected, due to the openings simulating the cross-road influence. Nevertheless, these velocities become rather lower $\left(|v| \leq 0.1 \mathrm{~m} \mathrm{~s}^{-1}\right)$ within the street canyon area.

\subsection{Temperature profiles}

The horizontal cross-section profiles of temperature at several heights above the road of the city canyon are shown in Figure 4 for the six scenarios simulated. The temperature profile for Scenario I is symmetrical as expected, while the profiles of all other scenarios (II throughout $\mathrm{VI}$ ), which have non-symmetrical heat sources, are non-symmetrical as well. For Scenario I, the maximum value of temperature $\left(24.5^{\circ} \mathrm{C}\right)$ near the building is found at the middle of height, i.e. $17.5 \mathrm{~m}$ above the road, caused by the road heat source only, contrary to Scenario II, which has a left-wall heat source only, and Scenario III, which has both road and left wall heat sources, where the temperature is increased to about $36^{\circ} \mathrm{C}$ at the same location. Scenarios IV and V, which have also a low wind speed $u_{a}=1 \mathrm{~m} \mathrm{~s}^{-1}$ (left-to-right wind) and $-1 \mathrm{~m} \mathrm{~s}^{-1}$ (right-to-left wind) above the buildings and street canyon, the values of temperature near the left building face are maximised again in the middle of the building height, taking the corresponding values of $41^{\circ} \mathrm{C}$ and $44^{\circ} \mathrm{C}$. For a right-to-left wind of moderate speed $u_{a}=-3 \mathrm{~m} \mathrm{~s}^{-1}$ (Scenario $\mathrm{VI}$ ), the temperatures near the left building and inside the canyon are reduced to values lower than the temperatures in calm conditions, i.e. $\left(28-29.5^{\circ} \mathrm{C}\right)$ and $\left(22-24^{\circ} \mathrm{C}\right)$, respectively. For Scenario I, the temperatures along the centreline of the street canyon are decreased from $28.5^{\circ} \mathrm{C}$ at $5 \mathrm{~m}$ above the road to $25^{\circ} \mathrm{C}$ at $17.5 \mathrm{~m}$ and $24.5^{\circ} \mathrm{C}$ at the top ( $30 \mathrm{~m}$ above the road). A rather small temperature decay is observed at higher levels and up to $50 \mathrm{~m}$ above road, where the temperature becomes $23.5^{\circ} \mathrm{C}$ for Scenario I. The maximum value inside the street canyon is $22^{\circ} \mathrm{C}$ for Scenario IV and $29^{\circ} \mathrm{C}$ for Scenario $\mathrm{V}$ at $17.5 \mathrm{~m}$ above road, while it is somewhat lower $\left(24^{\circ} \mathrm{C}\right)$ for Scenario $\mathrm{VI}$ at the same height. As expected, the temperature at the intermediate places of the street canyon is kept at lower levels than the temperature near the heat sources. The most adverse effects are found for Scenario II near the left wall at about the middle of the building height, which has a source of heat flux on the left wall face only, and for Scenarios III throughout VI, which have a source of heat flux both on the left wall face and road surface. It should be noted that the warm air near the building faces may deteriorate the interior room climatic conditions. This impact becomes stronger when a right-to-left wind of low speed blows over the street canyon (Scenario V) and indicates a slight improvement for a left-to-right wind of the same speed (Scenario IV), while it is considerably improved for a right-to-left wind of moderate speed (Scenario VI). Therefore, the scenarios studied can be ranked from the best to the worst in terms of the near wall temperatures, in the order I, VI, II, III, IV and $\mathrm{V}$.
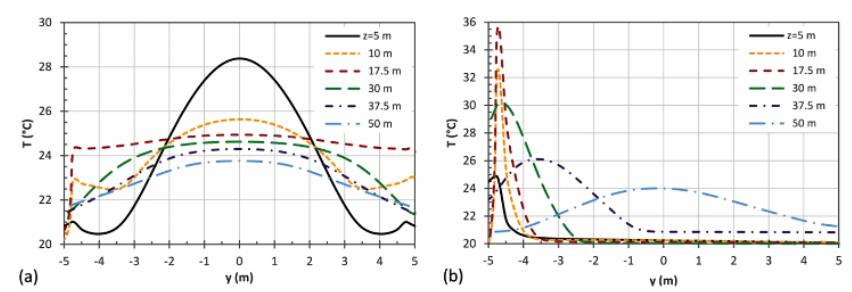

(a)
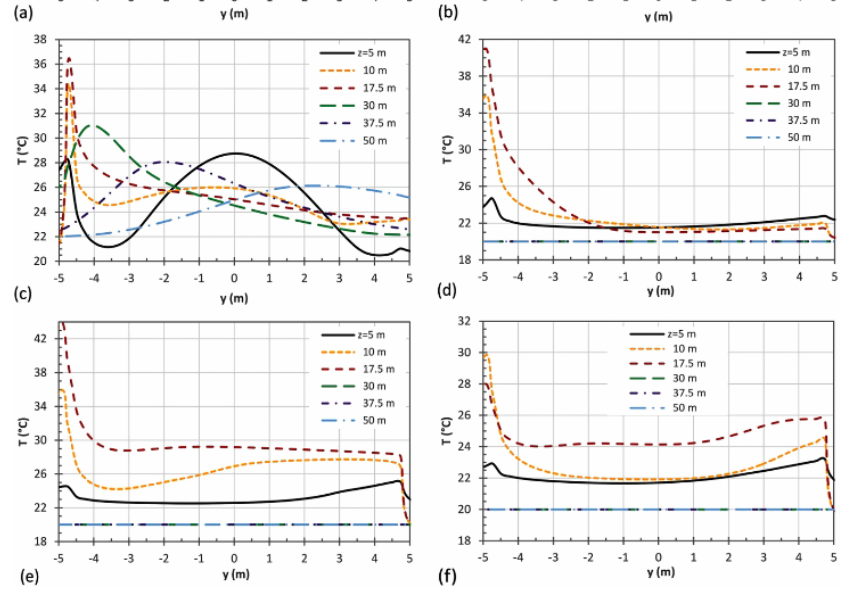

Figure 4. Horizontal cross section profiles of temperatures at several heights for the scenarios simulated: (a) Scenario I; (b) Scenario II; (c) Scenario III; (d) Scenario IV; (e) Scenario V and (f) Scenario VI 


\subsection{Velocity and temperature fields}

The velocity field inside and over the street canyon is shown in Figure 5 for the six scenarios studied, while the spatial temperature distribution inside and over the street canyon is shown in Figure 6. Paying attention on air temperatures near the left building wall (from 5 up to $30 \mathrm{~m}$ above road) shown in Figure 6 in conjunction with Figure 5, where existing air vortices are presented, it is confirmed that Scenarios III, IV and V are the worst of all, while Scenario VI presents somewhat lower temperatures. It seems that the weak or moderate wind blowing over the street canyon, irrespective of direction, favors the entrapment of hot air inside the street canyon and may adversely affect the indoors thermal comfort. Air trapping also contributes to an increase of pollutant concentrations emitted by the city traffic, which in turn may deteriorate the indoor air quality.

Scenarios I, II and III, shown in Figure 5a, b and c, indicate typical flow fields occurring in chimneys, where velocities initially are small enough, but are progressively increasing due to thermally induced buoyant forces. This increase has a low rate within the canyon due to the wall roughness. Over the street canyon, the flow starts again accelerating more intensely up to the height, where the thermal energy has been dissipated. For all scenarios shown in Figure 5, except Scenario I, vortices occur which trap air and prevent heat convection causing an increase of temperature and pollutant concentration, the most intense vortices are observed in Scenarios IV, V and VI, in the presence of weak wind.

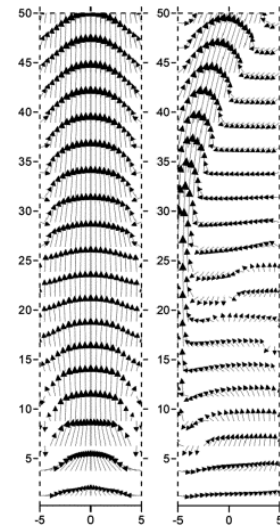

(a)

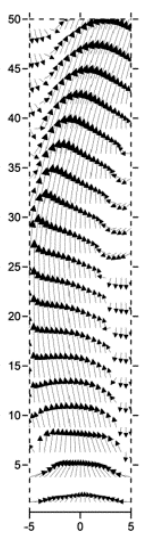

(c)

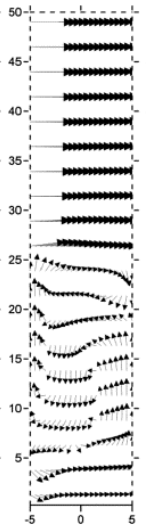

(d)

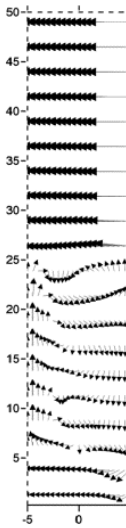

(e)

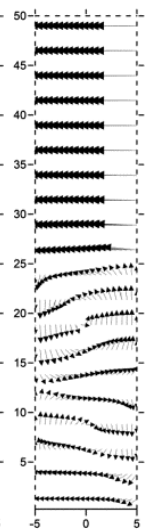

Figure 5. Velocity vector fields for the scenarios simulated: (a) Scenario I; (b) Scenario II; (c) Scenario III; (d) Scenario IV; (e) Scenario V; and (f) Scenario VI

It is noted, that for the most adverse scenarios, simulations with free boundaries at both sides and a symmetry upper boundary of the computational domain were carried out. The use of a symmetry upper boundary is in agreement with the wind boundary conditions over the street canyon. As the interest is focused within the street canyon, small differences in the velocity field and nearly the same results for the temperature field within the street canyon were found compared to the bounded domain.

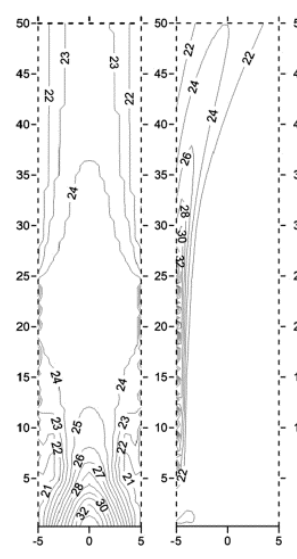

(a)

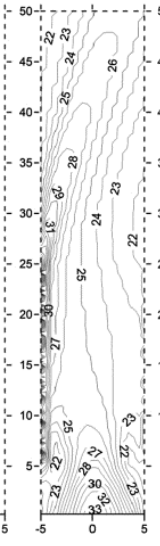

(c)

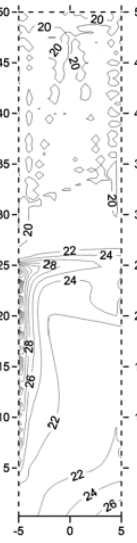

(d)

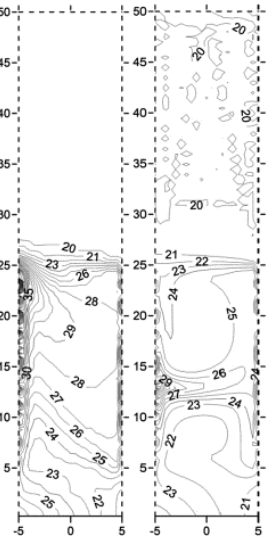

(e)

(f)
Figure 6. Iso-temperature contours within and over street canyon for the scenarios simulated: (a) Scenario I; (b) Scenario II; (c) Scenario III; (d) Scenario IV; (e) Scenario V; and (f) Scenario VI

\section{Conclusions}

From the present numerical simulation of flow and temperature field inside and over a street canyon, the following conclusions may be drawn:

In calm atmospheric conditions, the vertical velocities and temperatures near the left building face are in the ranges ( 0 to $0.4 \mathrm{~m} \mathrm{~s}^{-1}$ ) and $\left(27.5\right.$ to $36^{\circ} \mathrm{C}$ ), respectively, while on the opposite building face the velocities approach to zero and the temperatures are in the range $\left(21\right.$ to $\left.24.5^{\circ} \mathrm{C}\right)$. The flow field resembles that of chimneys.

In weak wind conditions, the vertical velocities and temperatures near the left building face are in the corresponding ranges $\left(-0.28\right.$ to $\left.0.36 \mathrm{~m} \mathrm{~s}^{-1}\right)$ and (24 to $\left.44^{\circ} \mathrm{C}\right)$, while on the opposite building face (-0.28 to $0.28 \mathrm{~m}$ $\left.\mathrm{s}^{-1}\right),\left(21\right.$ to $\left.28^{\circ} \mathrm{C}\right)$, respectively. Air trapping is rather favored by weak winds, which cause more intense vortices than in calm conditions, resulting to temperature increase which may adversely affect the indoor thermal comfort conditions.

In moderate wind conditions, the vertical velocities and temperatures near the left building face are in the corresponding ranges $\left(-0.85\right.$ to $\left.0.4 \mathrm{~m} \mathrm{~s}^{-1}\right)$ and (23.5 to $\left.29.5^{\circ} \mathrm{C}\right)$, while on the opposite building face $(-0.65$ to $\left.0.6 \mathrm{~m} \mathrm{~s}^{-1}\right),\left(20\right.$ to $\left.25.5^{\circ} \mathrm{C}\right)$. The moderate winds decrease air temperature under that occurring in calm conditions and improve the comfort climatic conditions.

Furthermore, air trapping causes increase of pollutant concentrations emitted by the city traffic, which may deteriorate indoor and outdoor air quality.

The authors intention is to extend the study of the phenomenon in a three-dimensional (3D) simulation in due course and compare the present findings with the results of future survey.

\section{References}

Battista G. and Mauri L. (2016), Numerical study of buoyant flows in street canyon caused by ground and building heating, Energy Procedia, 101, 1018-1025.

Bottillo S., de Lieto Vollaro A., Galli G. and Vallati A. (2014), CFD modeling of the impact of solar radiation in a tridimensional 
urban canyon at different wind conditions, Solar Energy, 102, 212-222.

De Lieto Vollaro A., de Simone G., Romagnoli R., Vallati A. and Bottillo S. (2014), Numerical study of urban canyon microclimate related to geometrical parameters, Sustainability, 6, 7894-7905.

Dimitrova R., Sini J.F., Richards K., Schatzmann M., Weeks M., Perez García E. and Borego C. (2009), Influence of thermal effects on the wind field within the urban environment, Boundary-Layer Meteorology, 131, 223-243.

Herbert J.M. and Herbert R.D. (2002), Simulation of the effects of canyon geometry on thermal climate in city canyons, Mathematics and Computers in Simulation, 59, 243-253.

Kim J.J. and Baik J.J. (2001), Urban street-canyon flows with ground heating, Atmospheric Environment, 35, 3395-3404.

Li L., Yang L., Zhanh L.J. and Jiang Y. (2012), Numerical Study on the Impact of Ground Heating and Ambient Wind Speed on Flow Fields in Street Canyons, Advances in Atmospheric Sciences, 29(6), 1227-1237.

Louka P., Vachon G., Sini J.-F., Mestayer P.G. and Rosant J.-M. (2002), Thermal effects on the airflow in a street canyonNantes '99 experimental results and model simulation. Water, Air, and Soil Pollution: Focus, 2, 351-364.

Nazarian N., Fan J., Sin T., Norford L. and Kleissl J. (2017), Predicting outdoor thermal comfort in urban environments: A 3D numerical model for standard effective temperature, Urban Climate, 20, 251-267.

Offerle B., Eliasson I., Grimmond C.S.B. and Holmer B. (2007), Surface heating in relation to air temperature, wind and turbulence in an urban street canyon, Boundary-Layer Meteorology, 122, 273-292.

Park S.B., Baik J.J., Raasch S. and Letzel M.O. (2012), A large-eddy simulation study of thermal effects on turbulent flow and dispersion in and above a street canyon, Journal of Applied Meteorology and Climatology, 51(2), 829-841.

Santiago J.L., Krayenhoff E.S. and Martilli A. (2014), Flow simulations for simplified urban configurations with microscale distributions of surface thermal forcing, Urban Climate, 9, 115-133.
Schwela D. (2000), Air Pollution and Health in Urban Areas, Reviews on Environmental Health, 15, 13-42.

Toparlar Y., Blocken B., Maiheub B. and Van Heijstd G.J.F. (2017), $A$ review on the CFD analysis of urban microclimate, Renewable and Sustainable Energy Reviews, 80, 1613-1640.

Uehara K., Murakami S., Oikawa S. and Wakamatsu S. (2000), Wind tunnel experiments on how thermal stratification affects flow in and above urban street canyons, Atmospheric Environment, 34, 1553-1562.

Venkatram A. and Schutle N. (2018), Urban Transportation and Air Pollution. Elsevier.

Wang P., Zhao D., Wang W., Mu H., Cai G. and Liao C. (2011), Thermal effect on pollutant dispersion in an urban street canyon, International Journal of Environmental Research, 5(3), 813-820.

Wang Y., Zhong K., Zhang N. and Kang Y. (2014), Numerical analysis of solar radiation effects on flow patterns in street canyons, Engineering Applications of Computational Fluid Mechanics, 8, 252-262.

Xie X., Huang Z., Wang J.S and Xie Z. (2005), Thermal effects on vehicle emission dispersion in an urban street canyon, Transportation Research Part D: Transport and Environment, 10(3), 197-212.

Xie X., Liu C.H. and Leung D.Y.C. (2007), Impact of building facades and ground heating on wind flow and pollutant transport in street canyons, Atmospheric Environment, 41, 9030-9049.

Xie X., Liu C.H., Leung D.Y.C. and Leung M.K.H. (2006), Characteristics of air exchange in a street canyon with ground heating, Atmospheric Environment, 40, 6396-6409.

Yaghoobian N., Kleissl J. and Paw U.K.T. (2014), An improved three-dimensional simulation of the diurnally varying streetcanyon flow, Boundary-Layer Meteorology, 153, 251-276.

Yannopoulos P.C. (2006), An improved integral model for plane and round turbulent buoyant jets, Journal of Fluid Mechanics, 547, 267-296.

Zakaria M., Abu Bakar M., Ridhwan J. and Mohd Hanafi M. (2014), CFD analysis of flow, pollutant dispersion and thermal effect in street canyons, Journal of Engineering and Technology, 5(1), 99-120. 